\title{
Concordia Discors, édité par B. Bolduc et H. Glodwyn
}

\section{Monica Pavesio}

\section{(2) OpenEdition}

\section{Journals}

\section{Edizione digitale}

URL: https://journals.openedition.org/studifrancesi/3074

DOI: $10.4000 /$ studifrancesi.3074

ISSN: 2421-5856

\section{Editore}

Rosenberg \& Sellier

\section{Edizione cartacea}

Data di pubblicazione: 1 juillet 2013

Paginazione: 451-452

ISSN: 0039-2944

\section{Notizia bibliografica digitale}

Monica Pavesio, «Concordia Discors, édité par B. Bolduc et H. Glodwyn», Studi Francesi [Online], 170

(LVII | II) | 2013, online dal 30 novembre 2015, consultato il 02 février 2023. URL: http://

journals.openedition.org/studifrancesi/3074 ; DOI: https://doi.org/10.4000/studifrancesi.3074

\section{Questo documento è stato generato automaticamente il 2 février 2023.}

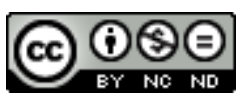

Creative Commons - Attribuzione - Non commerciale - Non opere derivate 4.0 Internazionale - CC BY NC-ND 4.0

https://creativecommons.org/licenses/by-nc-nd/4.0/ 


\title{
Concordia Discors, édité par B. Bolduc et H. Glodwyn
}

\author{
Monica Pavesio
}

\section{NOTIZIA}

Concordia Discors. Choix de communications présentées lors du $41^{\mathrm{e}}$ congrès de la North American Society for Seventeenth-Century French Literature, édité par B. BoLDuc et H. GLODWYN, Tübingen, Narr Verlag, 2011, 2 voll., pp. 252 et 245.

1 I volumi raccolgono una scelta delle comunicazioni presentate nel 2010 al convegno annuale della società nordamericana di studi sulla letteratura francese del Seicento.

2 Il tema del convegno, riassunto nella formula di Orazio "concordia discors», che vede l'universo formato dall'unione armoniosa di elementi apparentemente incompatibili, si propone di far riflettere sulle tensioni generatrici del Gran Secolo, e sui diversi approcci della critica letteraria francese, europea e nordamericana nei riguardi del XVII secolo.

3 Il convegno, svoltosi a New York, rende inoltre omaggio a due grandi secentisti nord americani, E. Henein e O. Ranum. Quest'ultimo, specialista dell'assolutismo, della Fronda e di Richelieu, apre il volume, con un interessante contributo sul contesto culturale e sociale in cui fu rappresentato il Cid e in cui si svolse la famosa Querelle.

4 Il primo volume contiene questioni di critica letteraria. Una prima sezione («Méthodes critiques») comprende cinque interventi che mettono a confronto i diversi approcci critici francesi, nord americani, inglesi. Interessante il contributo di E. BURY sulle somiglianze e differenze tra la storia culturale "à la française" e la cultural theory. Una seconda sezione è dedicata alla concordia discors nelle pratiche letterarie («Stratégie d'écriture») con una serie di contributi su: la pratica del pastiche nel XVII secolo (D. DENIS); il paradosso e la metalepsi nel romanzo secentesco (F. LAVocAT); gli scritti autobiografici in prima persona (J. SRIBNAI); l'ethos maschile nei Mémoires di Madame de 
La Guette (C. CARTMILL). Segue una terza sezione («Vérité et fiction») che mette a fuoco le tensioni dinamiche nella ricezione delle opere del Grand Siècle: C. THOURET studia il mutamento del legame di fedeltà al re nelle tragedie su Sophonisbe; M. HERSANT si occupa delle discordanze narrative nei Mémoires del cardinale di Retz e del duca di Saint-Simon. Una quarta sezione è dedicata al teatro, luogo dove le opposizioni sono più marcate. Illustrano le tensioni in ambito teatrale gli studi di A. SURGERS sulla scenografia del teatro barocco; di J. GROS DE GASQUET sui "farceurs tragédiens"; di F. CAVAILLÉ sull'eterogeneo pubblico parigino nel periodo che va dalla Querelle du Cid alla Pratique $d u$ Théâtre; di A. BONTEA sulla messa in scena delle opere di Molière.

Il secondo volume si apre con una sezione dedicata alle «Querelles galantes», con studi di S. ROLLIN sulle querelles attorno all'opera di Voiture; di N. FREIDEL sui dibattiti epistolari; di S. TONIoLo sulle lettere di Mme Deshoulières. Le querelles galanti incoraggiano una nuova arte di scrivere illustrata nella sezione «Rhétorique», con un contributo di R. Zaiser sulla "théorie de la pointe" nei trattati poetici secenteschi; un articolo di A. RÉGENT SUSINI sulla retorica dell'esposizione nella controversia antiprotestante; un saggio di L. SusinI sull'opposizione apparente tra stile semplice e stile figurato durante l'età classica.

Gli scrittori del xviI secolo hanno dato, nelle loro opere, una visione contrastata del mondo, sviluppando la difficile arte del compromesso, che riposa su uno spirito di sincretismo religioso, politico, estetico e filosofico, che viene illustrato nelle ultime tre sezioni del secondo volume, intitolate rispettivamente «Religion», "Croyances et superstitions» e «Formes du savoir».

7 I due volumi riuniscono, come si è potuto vedere, un grande numero di saggi, che apportano una varietà di approcci metodologici, a volte contrastanti, su un mosaico tematico che tocca tutti i livelli della pratica letteraria secentesca, dalla genesi alla ricezione. La ricchezza e la diversità dei testi riuniti, che noi abbiamo segnalato solo parzialmente, permettono la riflessione sulle forze dinamiche e contraddittorie che animarono ed armonizzarono un secolo come il Seicento e stabiliscono un rapporto proficuo tra la letteratura, la religione, la politica, l'arte e la musica. 